\title{
Usefulness of endoscopic ultrasonography in the clinical suspicion of biliary disease
}

\author{
David del Pozo, Susana Tabernero, Elvira Poves, Cecilia Sanz, Inmaculada Beceiro, Belén Costero, \\ Mónica Villafruela and Gloria Borrego \\ Unit of Gastroenterology. Hospital Universitario Príncipe de Asturias. Alcalá de Henares, Madrid. Spain
}

\begin{abstract}
Background and aims: endoscopic ultrasound (EUS) is a very sensitive and specific technique for the diagnosis of biliary diseases. This procedure has proven its usefulness in cases of high suspicion of biliary disease (history of gallstones and dilatation of the intrahepatic and/or extrahepatic bile ducts). We know less about its usefulness in cases of low suspicion of biliary pathology.

The aim of this study was to assess the diagnostic accuracy of EUS in patients with low suspicion of biliary disease (patients with dilatation of the biliary tract were excluded).

Methods: 33 patients with low suspicion of biliary disease were recruited in 12 months. All of them had no biliary findings in a previous abdominal ultrasound and computer tomography scan. All of them underwent EUS and were studied prospectively. The diagnosis was confirmed by surgery and/or by ERCP in patients with positive EUS or clinical follow-up in those with normal EUS. Time of followup was 9 months (range, 3-12 months).

Results: seventeen patients (51.5\%) presented with abnormal biliary findings on EUS ( 7 choledocholithiasis, 3 cholelithiasis, 2 choledocholithiasis + cholelithiasis and 5 microlithiasis).

Conclusion: EUS is a useful and safe procedure for diagnosing patients with low suspicion of biliary disease.
\end{abstract}

Key words: EUS. Choledocholithiasis. Cholelitiasis. Microlithiasis.

Del Pozo D, Tabernero S, Poves E, Sanz C, Beceiro I, Costero B, Villafruela M, Borrego G. Usefulness of endoscopic ultrasonography in the clinical suspicion of biliary disease. Rev Esp Enferm Dig 2011; 103: 345-348.

Received: $13-12-10$.

Accepted: 16-02-11.

Correspondence: David del Pozo Prieto. Unit of Gastroenterology. Hospital Universitario Príncipe de Asturias. Carretera Meco (M-121), s/n. 28805 Alcalá de Henares, Madrid. Spain.

e-mail: dpozo.hupa@salud.madrid.org

\section{BACKGROUND}

Endoscopic ultrasonography (EUS) is a very sensitive and specific technique for diagnosing biliary diseases as has been demonstrated in multiple studies (1-4). It has a similar diagnostic accuracy to endoscopic retrograde cholangiopancreatography (ERCP) (or even higher) and to microscopic examination of duodenal bile in the diagnosis of choledocholithiasis $(5,6)$. It is also the indicated procedure for diagnosing microlithiasis. Studies comparing magnetic resonance imaging (MRCP) to EUS in the diagnosis of choledocholithiasis show that both techniques are similar (7-15), although EUS may be more sensitive when small stones are present (12).

It is a safe procedure with a low rate of complications, similar to upper endoscopy $(16,17)$.

Several studies have assessed the risk of choledocholithiasis according to clinical, analytical data, and imaging techniques (18-29) in order to avoid invasive methods and its complications.

Patients with high suspicion of choledocholithiasis (image of stone inside the common duct along with compatible clinical and analytical data) must undergo ERCP (4).

Cases classified as moderate risk are often those with a clear antecedent of biliary disease, dilated bile duct and major analytical alteration. In these patients, it clearly seems that we need a sensitive technique for diagnosing biliary diseases (either USE or MRCP) before performing more invasive techniques (ERCP).

It is unclear the attitude to be followed in patients with low suspicion of choledocholithiasis (right upper quadrant or epigastric pain and/or slight analytical alteration when the conventional image tests are negative). There are many studies about the clinical significance of microlithiasis in acute pancreatitis (30-36) but there is no much information on the detection (and clinical significance) of microlithiasis in patients with suspicion of biliary pain, when the tradi- 
tional imaging techniques are normal. Nevertheless, patients with microlithiasis may develop severe complications as colicky pain, cholecystitis, cholangitis, and acute pancreatitis (37).

In this study we evaluate the usefulness of EUS in patients with low risk for choledocholithiasis, along with those patients without cholecistectomy and suspected biliary disease in which the traditional imaging tests are normal.

Patients with dyspepsia may have other diseases such as chronic pancreatitis or pancreatic tumours that can be diagnosed by EUS (38-44). Although this is not the objective of this study, this must be taken into account when assessing the usefulness of EUS.

\section{AIMS AND METHODS}

The aim of this study was to assess the diagnostic accuracy of EUS in patients with low suspicion of biliary disease (patients with dilatation of the biliary tract were excluded). Patients referred to our department with intermediate or low risk for biliary disease (right upper quadrant or epigastric pain and/or cholestasis in laboratory tests) based on the criteria published by Canto et al. (27) with normal results of abdominal ultrasound and computer tomography (CT) were selected. All of them underwent EUS and were studied prospectively. EUS were performed under conscious sedation by using the EG 3670 URK radial scanning echoendoscope (Pentax).

The diagnosis was confirmed by surgery and/or ERCP in patients with positive EUS or clinical follow-up in those with normal EUS. Time of follow-up was 9 months (3-15 months).

\section{RESULTS}

Thirty-three patients were selected in 12 months. All of them had no biliary findings in a previous abdominal

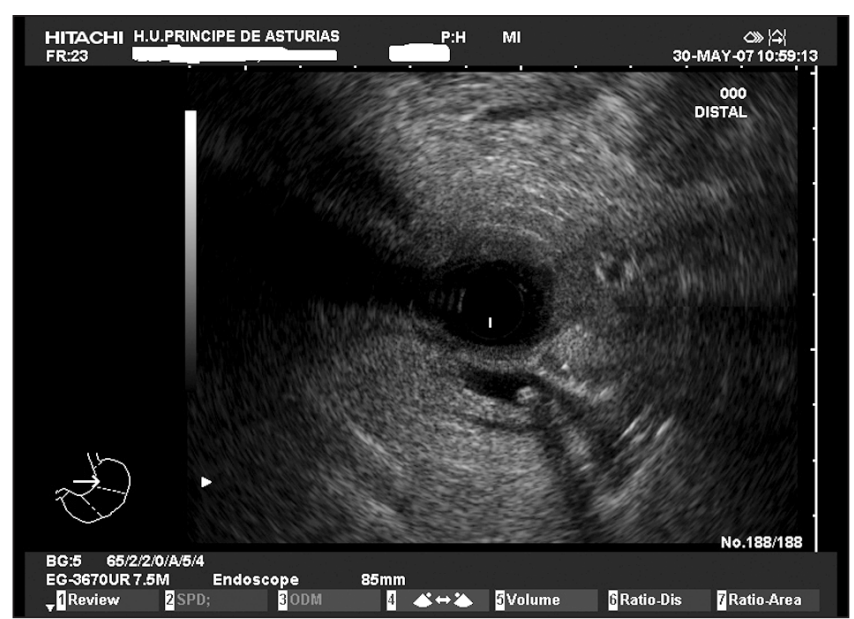

Fig. 1. ultrasound and CT scan (Fig. 1). The average age of these patients was 54 years. Seventeen patients $(51.5 \%)$ presented with abnormal biliary findings on EUS ( 7 choledocholithiasis, 3 cholelithiasis, 2 choledocholithiasis + cholelithiasis and 5 microlithiasis). The patients' characteristics are shown in table I. If microlithiasis was excluded, 12 patients $(36.6 \%)$ had findings on EUS, with a median age of 55 years.

The presence of other diagnoses as chronic pancreatitis (5 patients with 3 or more criteria) was considered as normal for the purpose of classifying patients. There were no other pancreatobiliary diagnoses. There were no endoscopic findings (peptic diseases).

The presence of cholestasis in the laboratory tests was not related to the presence of abnormal findings in the EUS.

The risk of having pathology was higher in the patients without previous cholecystectomy, although there were no differences if patients with microlithiasis were excluded.

All the patients with microlithiasis were women, and none of them had analytical alterations.

The time of follow-up of the patients with choledocholithiasis was 9 months. All of them underwent ERCP with lithiasis extraction, and all of them were asymptomatic at the end of the follow-up.

All the patients with microlithiasis were referred for cholecistectomy. Two of them were free of symptoms after a median of 10 months (6-14). One patient had the same symptoms as before the surgery. The other 2 were lost in the follow-up. There were no complications related to the EUS exploration.

\section{DISCUSSION}

In a high percentage of patients with low risk of biliary disease, EUS is able to detect pathology missed by conventional imaging studies (US, CT). The probability of biliary disease among patients with low risk of choledocholithiasis may be higher than previously reported.

The EUS is a useful and safe method for assessing patients with suspected biliary disease with no findings in other imaging techniques.

Table I.

\begin{tabular}{lll}
\hline & Abnormal EUS & Normal EUS \\
\hline Age & $53.6(27-74)$ & $54.8(32-81)$ \\
Women & 12 & 11 \\
Men & 3 & 5 \\
Cholestasis in LT & 7 & 7 \\
No cholestasis in LT & 11 & 8 \\
Cholecystectomy & 6 & 8 \\
No cholecystectomy & 11 & 8 \\
\end{tabular}


In addition, other pathologies may be diagnosed by EUS (such as chronic pancreatitis or peptic disease) that could be related to the symptoms of these patients.

There is no evidence that microlithiasis can cause right upper quadrant or epigastric pain and/or cholestasis in laboratory tests, but even excluding patients with microlithiasis, the findings are enough to be taken into account.

All the patients with choledocholithiasis detected by the EUS in this study remained free of symptoms after lithiasis extraction. All patients with microlithiasis underwent cholecystectomy, and about half of them had their symptoms resolved at the end of the follow-up. These data show that EUS is able to modify the natural history of the disease in about half of the patients studied.

EUS is usually performed after other conventional techniques as abdominal ultrasound or CT, and often with the only intention of making fine needle aspiration or getting more information of a known lesion. EUS, therefore, has so far been a second-line procedure for the study of patients with pancreatobiliary diseases.

Up until now, this is due to the low availability of technology so far and also to the small number of gastroenterologists trained in this technique. This situation is rapidly changing because the number of EUS devices is increasing, as is doing the number of trained gastroenterologists. This will increase the availability of this technique in coming years.

Another reason for the small number of explorations carried out compared with other procedures is the consideration of the EUS as invasive technique, although as has been already demonstrated, is a safe procedure. It is indicated to perform an upper endoscopy when necessary, though it has a similar rate of complications to the EUS without fine needle aspiration.

The data presented in this study support EUS to be taken into account as a first line exploration in the management of patients with suspected biliary disease.

The EUS also allows exploring the stomach and duodenum to look for peptic pathology. The development of more flexible echoendoscopes will make the endoscopic view very similar to that of the traditional endoscopes.

EUS is a growing demand technique that has low risks and leads to better decision-making in a significant number of patients with different diseases. Therefore, its inclusion in routine clinical practice must be considered (45).

In conclusion, EUS is a useful and safe procedure for diagnosing patients with low suspicion of biliary disease. Further studies with a higher number of patients are needed.

\section{REFERENCES}

1. Sgouros SN, Bergel C. Endoscopic ultrasonography versus other diagnostic modalities in the diagnosis of choledocholithiasis. Dig Dis Sci 2006;51:2280-6

2. Amouyal P, Amouyal G, Lévy P, Tuzet S, Palazzo L, Vilgrain V, et al. Diagnosis of choledocholithiasis by endoscopic ultrasonography. Gastroenterology 1994;106:1062-7.
3. Sugiyama M, Atomi Y. Endoscopic ultrasonography for diagnosing choledocholithiasis: a prospective comparative study with ultrasonography and computed tomography. Gastrointest Endosc 1997;45:143-6.

4. Williams EJ, Green J, I Beckingham, R Parks, Martin D, Lombard M. Guidelines on the management of common bile ducts stones (CBDs). Gut 2008;57:1004-21.

5. Queneau PE, Zeeh S, Lapeyre V, Thibault P, Heyd B, Carayon P, et al. Feasibility of and interest in combined endoscopic ultrasonography and biliary drainage in unexplained acute biliopancreatic disorders. Dig Dis Sci 2002;47:2020-4.

6. Dahan P, Andant C, Lévy P, Amouyal G, Dumont M, Erlinger S, et al. Prospective evaluation of endoscopic ultrasonography and microscopic examination of duodenal bile in the diagnosis of cholecystolithiasis in 45 patients with normal conventional ultrasonography. Gut 1996;38:277-281.

7. Verma D, Kapadia A, Eisen GM, Adler DG. MRCP vs. EUS for detection of choledocholithiasis. Gastrointest Endosc 2006;64:248-54.

8. de Lédinghen V, Lecesne R, Raymond JM, Gense V, Amouretti M, Drouillard J, et al. Diagnosis of choledocholithiasis: EUS or magnetic resonance cholangiography? A prospective controlled study. Gastrointest Endosc 1999;49:26-31.

9. Materne R, Van Beers BE, Gigot JF, Jamart J, Geubel A, Pringot J, et al. Extrahepatic biliary obstruction: magnetic resonance imaging compared with endoscopic ultrasonography. Endoscopy 2000;32:3-9.

10. Scheiman JM, Carlos RC, Barnett JL, Elta GH, Nostrant TT, Chey WD, et al. Can endoscopic ultrasound or magnetic resonance cholangiography replace ERCP in patients with suspected biliary disease? A cost trial and cost analysis. Am J Gastroenterol 2001;96:2900-3.

11. Ainsworth AP, Rafaelsen SR, Wamberg PA, Durup J, Pless TK, Mortersen MB. Is there a difference in diagnostic accuracy and clinical impact between endoscopic ultrasonography and magnetic resonance cholangiopancreatography? Endoscopy 2003;35:1029-32.

12. Kondo $\mathrm{S}$, Isayama $\mathrm{H}$, Akahane $\mathrm{M}$. Detection of common bile duct stones: comparison between endoscopic ultrasonography, magnetic resonance cholangiography and helical-computed-tomographic cholangiography. Eur J Radiol 2005;54:271-5.

13. Aube C, Delorme B, Yzet T, Burtin P, Lebigot J, Pessaux P, et al. MR cholangiopancreatography versus endoscopic sonography in suspected common bile duct lithiasis: a prospective, comparative study. Am J Roentgenol 2005;184:55-62.

14. Ledro-Cano D. Suspected choledocholithiasis: endoscopic ultrasound or magnetic resonance cholangio-pancreatography? A systematic review. Eur J Gastroenterol Hepatol 2007;19:1007-11

15. Ainsworth AP, Rafaelsen SR, Wamberg PA, Durup J, Pless TK, Mortensen MB. Is there a difference in diagnostic accuracy and clinical impact between endoscopic ultrasonography and magnetic resonance cholangiopancreatography? Endoscopy 2003;35:1029-32.

16. Rösch T, Dittler HJ, Fockens P, Yasuda K, Lightdale C. Major complications of endoscopic ultrasonography: results of a survey of 42105 cases [abstract]. Gastrointest Endosc 1993;39:341

17. Adler DG, Jacobson BC, Davila RE, Hirota WK, Leighton JA, Qureshi WA, et al.; ASGE. Standards of Practice Committee (2005) ASGE guideline: complications of EUS. Gastrointest Endosc 2005;61:8-12.

18. Barkun AN, Barkun JS, Fried GM, Ghitulescu G, Steinmetz O, Pham $\mathrm{C}$, et al. Useful predictors of bile duct stones in patients undergoing laparoscopic cholecystectomy. McGill gallstone Treatment Group. Ann Surg 1994;220:32-9.

19. Onken JE, Arm SR, Eisen GM, Williams DM, Bouras EP, DeLong ER, et al. Predicting the presence of choledocholitiasis in patients with symptomatic cholelithiasis. Am J Gastroenterol 1996;91:762-7.

20. Kim KH, Kim W, Lee HI, Sung CK. Prediction of common bile duct stones: its validation in laparoscopic cholecystectomy. Hepatogastroenterology 1997;44:1574-9.

21. Abboud PA, Malet PF, Berlin JA, Staroscik R, Cabana MD, Clarke JR, et al. Predictors of common bile duct stones prior to cholecystectomy: a meta-analysis. Gastrointest Endosc 1996;44:450-5.

22. Prat F, Meduri B, Ducot B, Chiche R, Salimbeni-Bartolini R, Pelletier G. Prediction of common bile duct stones by non-invasive tests. Ann Surg 1999;229:362-8.

23. Meroni E, Bisagni P, Bona S, Fumagalli U, Zago M, Rosati R, et al. Pre-operative endoscopic ultrasonography can optimise the management of patients undergoing laparoscopic cholecystectomy with abnormal liver function tests as the sole risk factor for choledocholithiasis: a prospective study. Dig Liver Dis 2004;36:73-7. 
24. Trondsen E, Edwin B, Reiertsen O, Faerden AE. Prediction of common bile duct stones prior to cholecystectomy. A prospective validation of a discriminant analysis function. Arch Surg 1998;133:162-6.

25. Aljebrren A, Azzam N, Eloubeidi. Prospective study of endoscopic ultrasound perfomance in suspected choledocholithiasis. J Gastroenterol Hepatol 2008;23:741-5.

26. Palazzo L, O'Toole D. EUS in common bile duct stones. Gastrointest Endosc 2002;56(4 Supl.):S49-57.

27. Canto MI, Chak A, Stellato T, Sivak MV. Endoscopic ultrasonography versus cholangiography for the diagnosis of choledocholithiasis. Gastrointest Endosc 1998;47:439-48.

28. Buscarini E, Tansini P, Vallisa D, Zambelli A, Buscarini L. EUS for suspected choledocholithiasis: Do benefits outweigh costs? A prospective, controlled study. Gastrointest Endosc 2003;57:510-8.

29. Tse F, Liu L, Barkun AN, Armstrong D, Bchir MB, Moayyedi P. EUS: a meta-analysis of test performance in suspected choledocholithiasis. Gastrointest Endosc 2008;67:235-44.

30. Petrone MC, Arcidiacono PG, Testoni PA. Endoscopic ultrasonography for evaluating patients with recurrent pancreatitis. World J Gastroenterol 2008;14:1016-22.

31. Wilcox CM, Varadarajulu S, Eloubeidi M. Role of endoscopic evaluation in idiopathic pancreatitis: a systematic review. Gastrointest Endosc 2006;63:1037-45.

32. Tandon M, Topazian M. Endoscopic ultrasound in idiopathic acute pancreatitis. Am J Gastroenterol 2001;96:705-9.

33. Frossard JL, Sosa-Valencia L, Amouyal G, Marty O, Hadengue A, Amouyal P. Usefulness of endoscopic ultrasonography in patients with "idiopathic', acute pancreatitis. Am J Med 2000;109:196-200.

34. Norton SA, Alderson D. Endoscopic ultrasonography in the evaluation of idiopathic acute pancreatitis. Br J Surg 2000;87:1650-5.

35. Yusoff IF, Raymond G, Sahai AV. A prospective comparison of the yield of EUS in primary vs recurrent idiopathic acute pancreatitis. Gastrointest Endosc 2004;60:673-8.
36. Vila JJ, Borda F, Jiménez FJ. The role of endoscopic ultrasonography in the etiological evaluation of idiopathic acute pancreatitis. Rev Esp Enferm Dig 2008;100(2):90-7.

37. Jüngst C, Kullak-Ublick GA, Jungst D. Gallstone disease: Microlithiasis and sludge. Best Pract Res Clin Gastroenterol 2006;20(6):1053-62.

38. Tandon M, Topazian M. Endoscopic ultrasound in idiopathic acute pancreatitis. Am J Gastroenterol 2001;96:705-9.

39. Sahai AV, Mishra G, Penman ID, Williams D, Wallace MB, Hadzijahic N, et al. EUS to detect evidence of pancreatic disease in patients with persistent or nonspecific dyspepsia. Gastrointest Endosc 2000;52: 293-8.

40. Akahoshi K, Chijiiwa Y, Nakano I, Nawata H, Ogawa Y, Tanaka M, et al. Diagnosis and staging of pancreatic cancer by endoscopic ultrasound. Br J Radiol 1998;71:492-6.

41. Al-Kaisi N, Siegler EE. Fine needle aspiration cytology of the pancreas. Acta Cytol 1989;33:145-52.

42. Rosch T, Lorenz R, Braig C, Classen M. Endoscopic ultrasonography in diagnosis and staging of pancreatic and biliary tumors. Endoscopy 1992;24(Supl. 1):304-8.

43. Palazzo L, Roseau G, Gayet B, Vilgrain V, Belghiti J, Fekete F, Paolaggi JA. Endoscopic ultrasonography in the diagnosis and staging of pancreatic adenocarcinoma. Results of a prospective study with comparison to ultrasonography and CT scan. Endoscopy 1993;25:14350 .

44. Wiersema MJ, Hawes RH, Lehman GA, Kochman ML, Sherman S, Kopecky KK. Prospective evaluation of endoscopic ultrasonography and endoscopic retrograde cholangiopancreatography in patients with chronic abdominal pain of suspected pancreatic origin. Endoscopy 1993;25:555-64.

45. Poves E, del-Pozo D, Tabernero S, Bardina A, Martínez P, Castillo MC. Clinical impact of high-definition endoscopic ultrasonography (EUS) in a district hospital. Rev Esp Enferm Dig 2010;102:698703. 